\title{
Sequential Michael addition/retro-Claisen condensation of 1,3-diarylpropan-1,3-diones with nitrostyrenes: one-step synthesis of 4-nitro-1,3-diarylbutan-1-ones
}

\author{
ZHENG LI*®, HAO LU, ZHENRONG LIU and XIAOLONG MA \\ College of Chemistry and Chemical Engineering, Northwest Normal University, Lanzhou 730070, Gansu, \\ People's Republic of China \\ E-mail: lizheng@nwnu.edu.cn
}

MS received 26 November 2018; revised 24 January 2019; accepted 5 February 2019; published online 21 March 2019

\begin{abstract}
The sequential Michael addition/retro-Claisen condensation of 1,3-diarylpropan-1,3-diones with nitrostyrenes is described. 4-Nitro-1,3-diarylbutan-1-ones were efficiently synthesized in good to high yield under mild, transition-metal-free condition. This one-step method involving sequential carbon-carbon bond formation and cleavage provides a good alternative to the synthesis of various $\gamma$-nitro ketones.
\end{abstract}

Keywords. Michael addition; retro-Claisen condensation; $\gamma$-nitro ketone; carbon-carbon bond formation; carbon-carbon bond cleavage.

\section{Introduction}

The Michael addition is one of the most useful methods for the mild formation of carbon-carbon bonds. ${ }^{1}$ Meanwhile, retro-Claisen condensation is an efficient method for the cleavage of carbon-carbon bonds. ${ }^{2}$ The combination of Michael addition and retro-Claisen condensation will possibly produce a novel synthesis.

As one of the main classes of ketone compounds, $\gamma$ nitro ketones are widely used as intermediates for the synthesis of various functionalized carbocycles. ${ }^{3-8}$ The reported typical synthetically viable procedures for the construction of $\gamma$-nitro ketones include: i) the conjugate addition of nitromethane to chalcone; ${ }^{9-13}$ ii) the detrifluoroacetylative Michael addition of 1-trifluoromethyl1,3-diketones to conjugated nitroalkenes; ${ }^{14}$ iii) the amine-catalyzed Michael addition of ketones to nitrostyrene; ${ }^{15-25}$ iv) the nickel-catalyzed decarboxylative Michael addition of $\beta$-ketoacids to nitrostyrenes ${ }^{26,27}$ (Scheme 1). However, some drawbacks, such as low yield, limited diversity and expensive substrates, still remains in the existing methods. Therefore, the development of other synthetic methods for their direct preparation from readily accessible materials is required.
Here, we report a novel method to 4-nitro-1, 3-diarylbutan-1-ones through the sequential Michael addition/retro-Claisen condensation reactions of 1,3diarylpropan-1,3-diones with nitrostyrenes by using DBU as a catalyst and ethanol as a reagent and solvent under mild condition.

\section{Experimental}

\subsection{General information}

${ }^{1} \mathrm{H}$ NMR and ${ }^{13} \mathrm{C}$ NMR spectra were obtained with Mercury$400 \mathrm{BB}$ or Mercury-600 BB instrument using $\mathrm{CDCl}_{3}$ as solvent and $\mathrm{Me}_{4} \mathrm{Si}$ as the internal standard. High-resolution mass spectra (HRMS) (ESI) were obtained with a Bruker Daltonics APEX II 47e and Orbitrap Elite mass spectrometer. 1,3-Diarylpropan-1,3-diones ${ }^{28}$ and nitrostyrenes ${ }^{29}$ were synthesized according to the literature procedure.

\subsection{General procedure for the synthesis of 4-nitro-1,3-diarylbutan-1-ones (3a-3t)}

The mixture of 1,3-diarylpropan-1,3-diones $\mathbf{1}(0.5 \mathrm{mmol})$, nitrostyrenes $2(0.5 \mathrm{mmol})$ and DBU $(0.05 \mathrm{mmol})$ in $\mathrm{EtOH}$

\footnotetext{
*For correspondence

Electronic supplementary material: The online version of this article (https://doi.org/10.1007/s12039-019-1603-z) contains supplementary material, which is available to authorized users.
} 


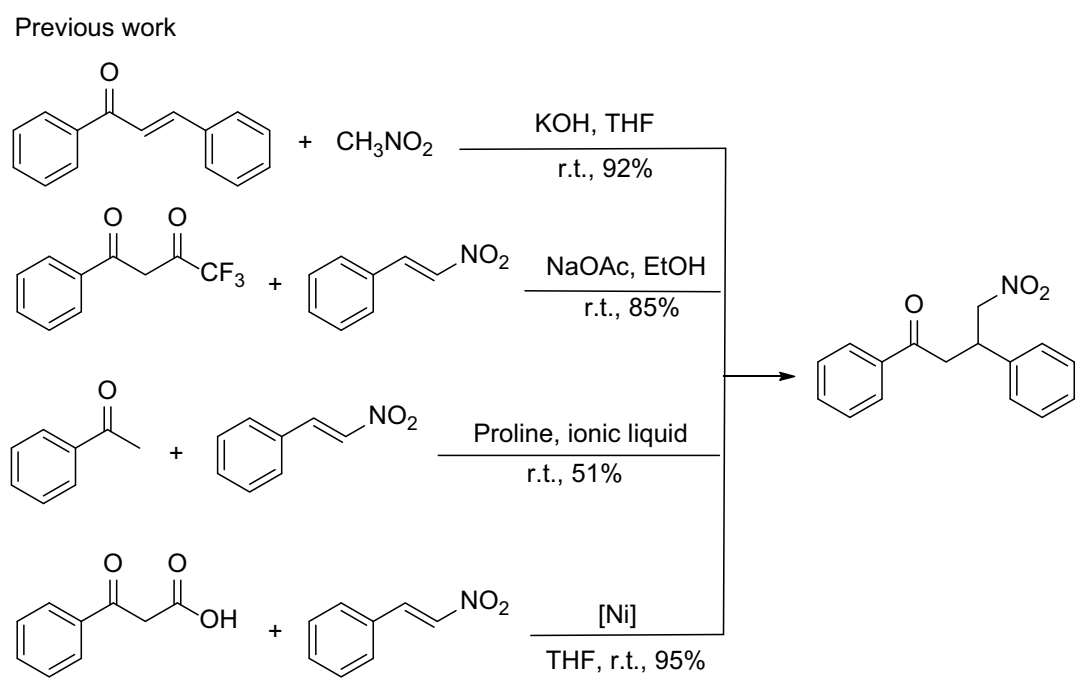

This work

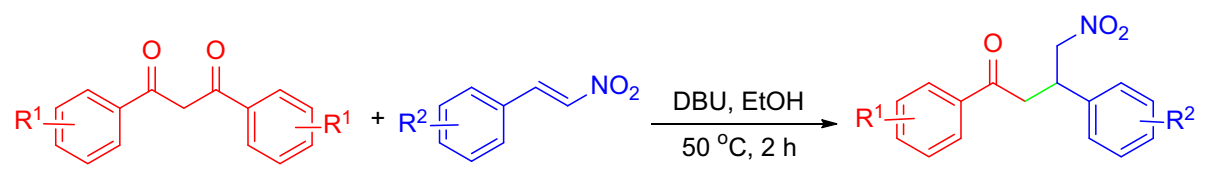

Scheme 1. Preparation of 4-nitro-1,3-diarylbutan-1-ones.

Table 1. Optimization of the reaction conditions ${ }^{\mathrm{a}}$.<smiles>O=C(CC(=O)c1ccccc1)c1ccccc1</smiles>

\begin{tabular}{lccc}
\hline Entry & Catalyst & Solvent & Yield [\%] $^{\mathrm{b}}$ \\
\hline 1 & - & $\mathrm{EtOH}$ & 0 \\
2 & $\mathrm{NaOH}$ & $\mathrm{EtOH}$ & 20 \\
3 & $\mathrm{KOH}$ & $\mathrm{EtOH}$ & 9 \\
4 & $\mathrm{NaHCO}_{3}$ & $\mathrm{EtOH}$ & 33 \\
5 & $\mathrm{~K}_{2} \mathrm{CO}_{3}$ & $\mathrm{EtOH}$ & 40 \\
6 & $\mathrm{Cs}_{2} \mathrm{CO}_{3}$ & $\mathrm{EtOH}$ & 50 \\
7 & $\mathrm{DABCO}$ & $\mathrm{EtOH}$ & 65 \\
8 & $\mathrm{DMAP}$ & $\mathrm{EtOH}$ & 76 \\
9 & $\mathrm{EtOH}$ & 55 \\
10 & $\mathrm{EBU}$ & $\mathrm{EeH}$ & 85 \\
11 & $\mathrm{MBU}$ & $i-\mathrm{PrOH}$ & Trace \\
12 & $\mathrm{DBU}$ & $n-\mathrm{BuOH}$ & 23 \\
13 & $\mathrm{DBU}$ & & 0 \\
\hline
\end{tabular}

${ }^{a}$ Reaction conditions: 1a $(0.5 \mathrm{mmol}), \mathbf{2 a}(0.5 \mathrm{mmol})$, catalyst $(0.05 \mathrm{mmol})$ in alcohol $(3 \mathrm{~mL})$ was stirred at $50^{\circ} \mathrm{C}$ for $2 \mathrm{~h}$. ${ }^{\mathrm{b}}$ Isolated yield.

(3 mL) was stirred at $50^{\circ} \mathrm{C}$ for $2 \mathrm{~h}$. The reaction was monitored by TLC. After the completion of the reaction, the resulting mixture was concentrated under reduced pressure. The residue was isolated by column chromatography using petroleum ether and ethyl acetate (v/v 8:1) as eluent to give the pure product. The analytical data for products are given in the Supplementary Information section. 
Table 2. Synthesis of 4-nitro-1,3-diarylbutan-1-ones from symmetrical 1,3diarylpropan-1,3-diones and nitrostyrenes ${ }^{\mathrm{a}}$.<smiles>CCCCC(=O)CC(=O)CC(Cc1ccccc1)C(=O)CC(C[N+](=O)[O-])c1ccc(C)cc1</smiles><smiles></smiles><smiles>O=C(CC(c1ccc(F)cc1)[N+](=O)[O-])c1ccccc1</smiles>

3e $65 \%$<smiles>O=C(CC(C[N+](=O)[O-])c1ccccc1Cl)c1ccccc1</smiles>

3f $71 \%$<smiles>O=C(CC(C[N+](=O)[O-])c1cccc(Br)c1)c1ccccc1</smiles>

3g $69 \%$<smiles>O=C(CC(C[N+](=O)[O-])c1ccco1)c1ccccc1</smiles>

3j $68 \%$<smiles>COc1ccc(C(CC(=O)c2ccc(C)cc2)C[N+](=O)[O-])cc1</smiles>

3 m $89 \%$<smiles>O=C(CC(C[N+](=O)[O-])c1ccccc1)c1cccs1</smiles>

3p $65 \%$<smiles>CC(=O)CC(C[N+](=O)[O-])c1ccccc1</smiles>

$0 \%$<smiles>O=C(CC(C[N+](=O)[O-])c1ccccc1)c1ccccc1</smiles>

3h $59 \% \quad \mathrm{NO}_{2}$<smiles>O=C(CC(C[N+](=O)[O-])c1cccs1)c1ccccc1</smiles>

3k $67 \%$<smiles>Cc1ccc(C(=O)CC(C[N+](=O)[O-])c2ccccc2Cl)cc1</smiles>

3n $85 \%$<smiles>COc1ccc(C(CC(=O)c2cccs2)C[N+](=O)[O-])cc1</smiles>

$3 q 70 \%$

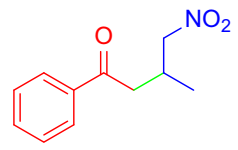

$0 \%$<smiles>O=C(CC(C[N+](=O)[O-])c1ccc2c(c1)OCO2)c1ccccc1</smiles>

3i $72 \%$<smiles>Cc1ccc(C(=O)CC(C[N+](=O)[O-])c2ccccc2)cc1</smiles>

31 $87 \%$<smiles>O=C(CC(C[N+](=O)[O-])c1ccccc1)c1ccccc1</smiles>

Br $3077 \%$<smiles>O=C(CC(C[N+](=O)[O-])c1cccc(Br)c1)c1cccs1</smiles>

3r $62 \%$

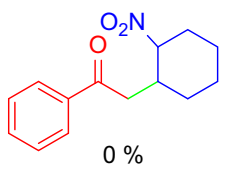

${ }^{a}$ Reaction conditions: 1,3 -diarylpropan-1,3-diones $(0.5 \mathrm{mmol})$, nitrostyrenes $(0.5 \mathrm{mmol})$ and DBU $(0.05 \mathrm{mmol})$ in $\mathrm{EtOH}(3 \mathrm{~mL})$ was stirred at $50^{\circ} \mathrm{C}$ for $2 \mathrm{~h}$.

\section{Results and Discussion}

Initially, the reaction of 1,3-diphenylpropan-1,3-dione (1a) with nitrostyrene (2a) as a model reaction was attempted to synthesize 4-nitro-1,3-diphenylbutan-1one (3a) under a variety of conditions. It was found that the reaction of $1 \mathbf{a}$ with $\mathbf{2 a}$ in ethanol could not give any product in the absence of a base (Table 1, entry 1 ). 

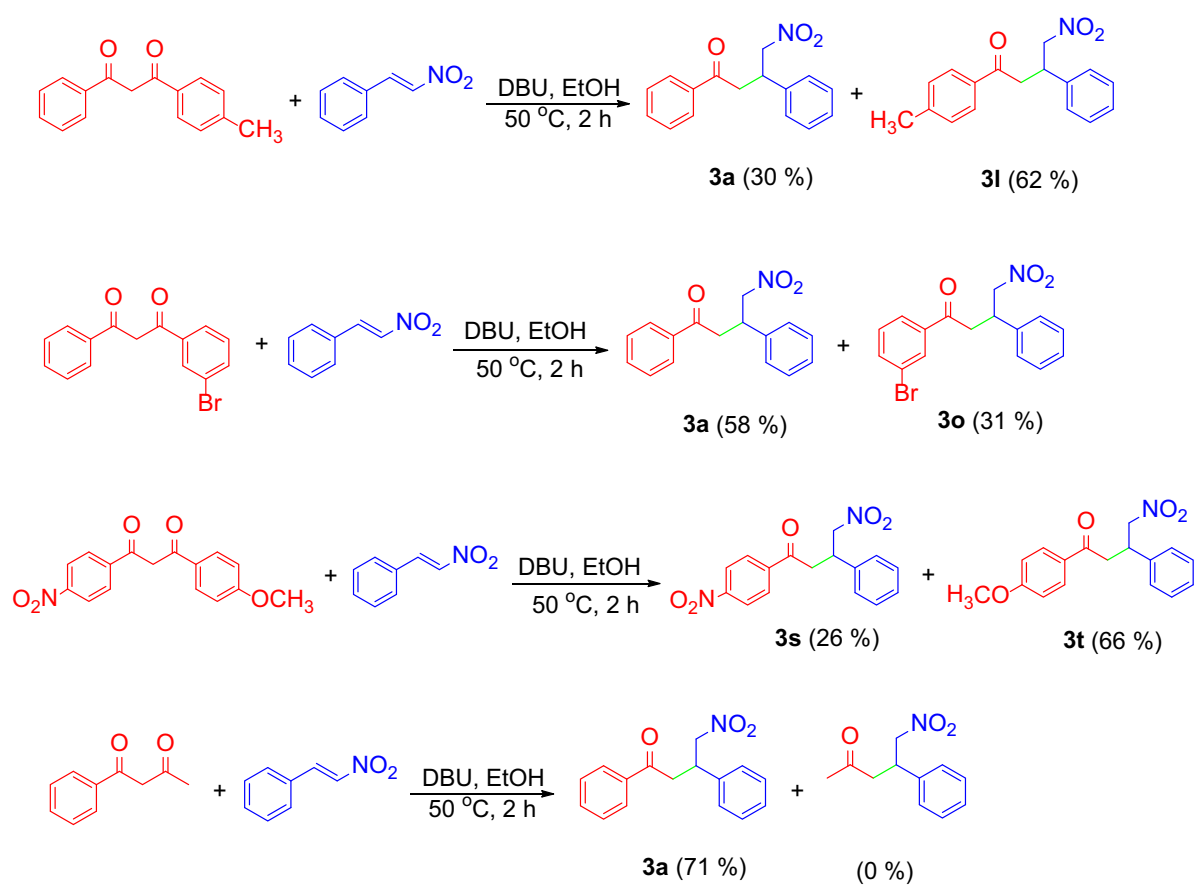

Scheme 2. Synthesis of 4-nitro-1,3-diarylbutan-1-ones from unsymmetrical 1,3-diarylpropan-1,3-diones and nitrostyrene.

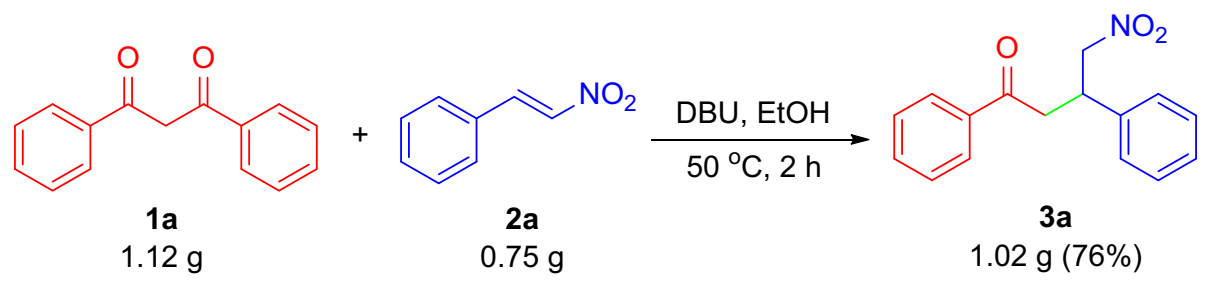

Scheme 3. Practical synthesis of $\mathbf{3 a}$ on gram scale.

However, the reaction could afford $\mathbf{3 a}$ in $20 \%$ yield in the presence of 0.1 equiv. of $\mathrm{NaOH}$ in ethanol at $50^{\circ} \mathrm{C}$ (entry 2). In order to improve the yield of $\mathbf{3 a}$, other bases, such as $\mathrm{KOH}, \mathrm{NaHCO}_{3}, \mathrm{~K}_{2} \mathrm{CO}_{3}, \mathrm{Cs}_{2} \mathrm{CO}_{3}$, DABCO, DMAP, $\mathrm{Et}_{3} \mathrm{~N}$ and DBU, as catalysts were examined (entries 310). All bases could catalyze the reaction to produce 3a in low to high yield. The best yield of $\mathbf{3 a}(85 \%)$ was obtained by using DBU as a catalyst (entry 10). Because ethanol in this reaction acted as a reactant and solvent, other alcohols, such as $\mathrm{MeOH}$, i-PrOH and $n-\mathrm{BuOH}$, were also attempted for the synthesis of 3a. However, no better yield of $\mathbf{3 a}$ was observed compared with ethanol (entries 11-13).

Under the optimized conditions, the synthesis of 4nitro-1,3-diarylbutan-1-ones (3a-3r) were examined by reactions of symmetrical 1,3-diarylpropan-1,3-diones and various nitrostyrenes catalyzed by DBU in ethanol at $50{ }^{\circ} \mathrm{C}$. The results are summarized in Table 2 . It was found that various symmetrical 1,3-diarylpropan1,3-diones and nitrostyrenes bearing aromatic rings and heteroaromatic rings could afford the corresponding products in good to high yield. The substituents on aromatic rings including electron-donating $\left(\mathrm{CH}_{3}, \mathrm{CH}_{3} \mathrm{O}\right)$ and electron-withdrawing $\left(\mathrm{F}, \mathrm{Cl}, \mathrm{Br}, \mathrm{NO}_{2}\right)$ groups did not show obvious effect on the yield. In contrast, the attempts for the reaction of pentan-2,4-dione with nitrostyrene (2a), the reaction of 1,3-diphenylpropan1,3-dione (1a) with nitropropene, and 1a with 1nitrocyclohexene were not successful.

In addition, the reactions of unsymmetrical 1,3-diaryl propan-1,3-diones with nitrostyrenes under standard condition also proceeded smoothly. However, two kinds of 4-nitro-1,3-diarylbutan-1-ones were generally produced. For example, the reaction of 1-phenyl-3- $(p-$ tolyl)propan-1,3-dione with nitrostyrene (2a) could give $3 \mathbf{a}(30 \%)$ and $3 \mathbf{l}(62 \%)$. The reaction of 1 (3-bromophenyl)-3-phenylpropan-1,3-dione with nitro styrene (2a) could give 3a (58\%) and 3o (31\%). The reaction of 1-(4-nitrophenyl)-3-(4-methoxyphenyl) propan-1,3-dione with nitrostyrene (2a) could give 

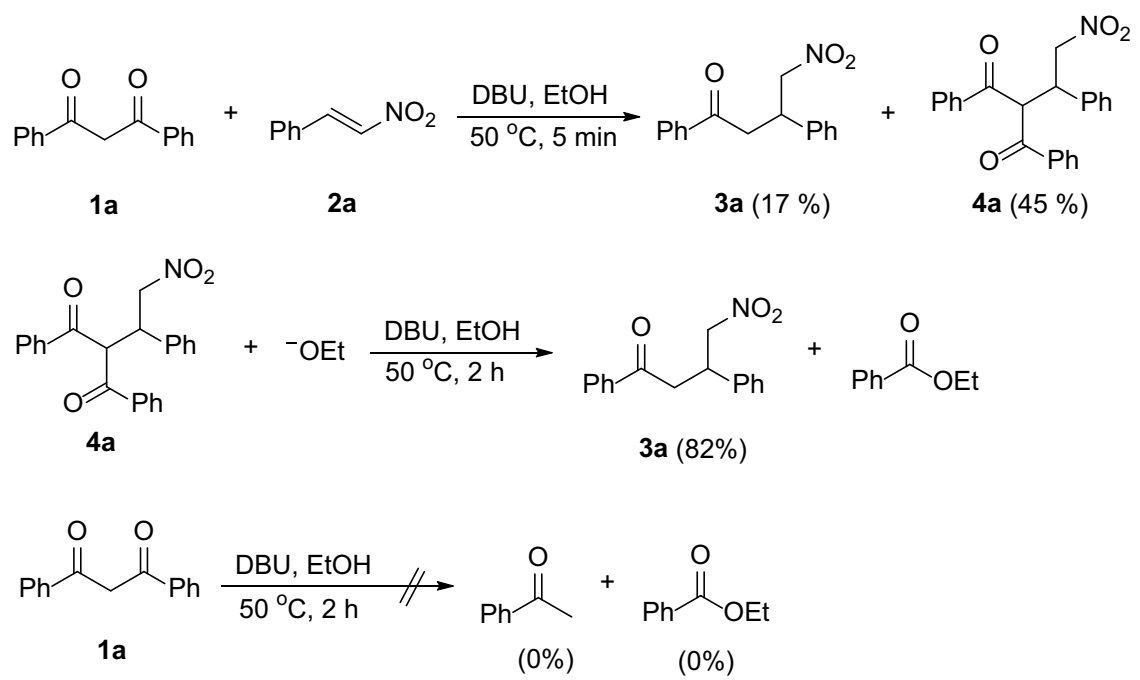

Scheme 4. Control experiments.

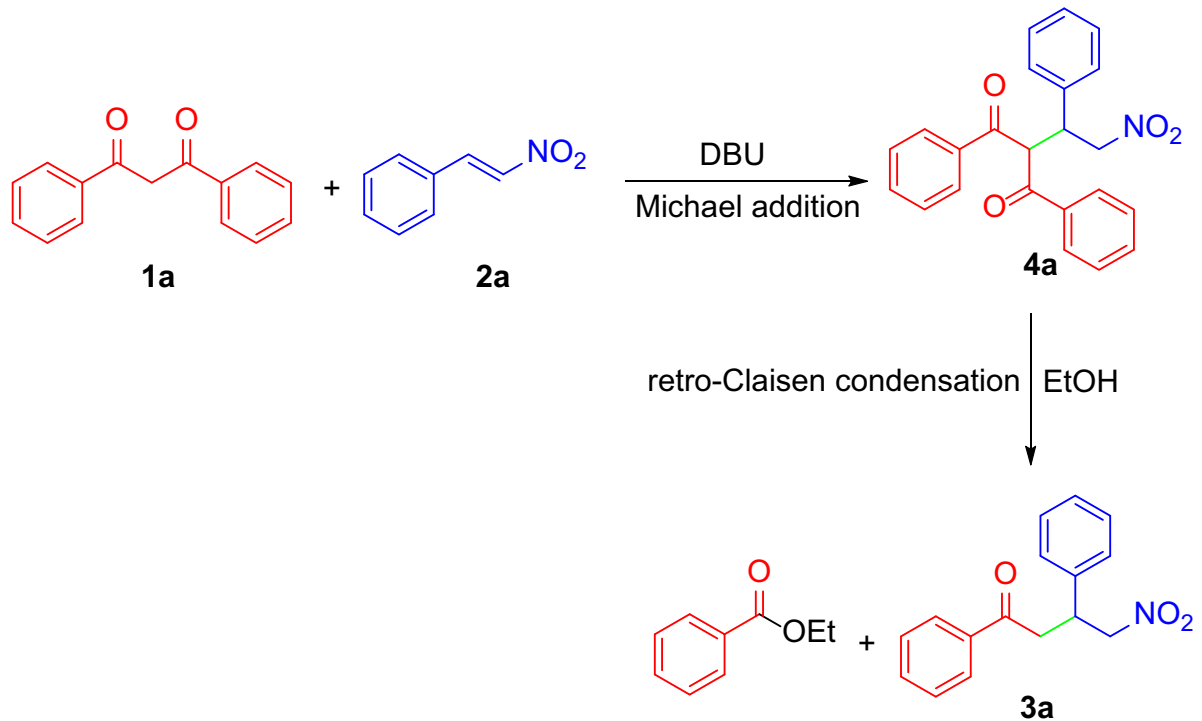

Scheme 5. Possible mechanism for the synthesis of 3a.

3s $(26 \%)$ and 3t (66\%) (Scheme 2). These results indicated that for the unsymmetrical 1,3-diarylpropan1,3-diones, the reactions were more advantageous to the products including an electron-donating group on aromatic rings than the ones including an electronwithdrawing group. In addition, aryl-alkyl ketone, such as 1-phenylbutan-1,3-dione, as a substrate was also attempted for the reaction, but only one product $\mathbf{3 a}$ (71\%) was observed.

With the success over generality of the protocol, the reaction of 1,3-diphenylpropan-1,3-dione (1a) with nitrostyrene (2a) was also performed on a gram scale. The reaction of $1.12 \mathrm{~g}$ of $\mathbf{1 a}$ with $0.75 \mathrm{~g}$ of $\mathbf{2 a}$ in the presence of $76 \mathrm{mg}$ of DBU in EtOH (12 mL) was performed under the optimized condition to give $1.02 \mathrm{~g}$ of $\mathbf{3 a}$ in $76 \%$ isolated yield. This success of gram scale reaction further showed the potency of optimized condition for the bulk processes (Scheme 3).

Control experiments were conducted as shown in Scheme 4. Treatment of 1,3-diphenylpropan-1,3-dione (1a) with nitrostyrene (2a) under the standard conditions for only $5 \mathrm{~min}$ gave a mixture of the desired product 3a $(17 \%)$ and a Michael addition product 4a (45\%), which could be isolated and identified by NMR spectra (Scheme 4, Eq. 1). Under the standard conditions, the isolated 4a could react with a small concentration of ethoxide ion formed by DBU and $\mathrm{EtOH}$ in the system to produce 3a in high yield through retro-Claisen condensation (Scheme 4, Eq. 2). This indicated that $\mathbf{4 a}$ is the intermediate of the formation of product $3 \mathbf{a}$. In addition, the treatment of $\mathbf{1 a}$ in the absence of nitrostyrene (2a) was also tested under standard conditions. However, 
the possible product, acetophenone, was not observed (Scheme 4, Eq. 3). This implied that retro-Claisen condensation could not take place between substrate 1a and EtOH.

Based on the above control experiments, a plausible mechanism is proposed for the synthesis of $\mathbf{3 a}$ (Scheme 5). Firstly, the reaction of 1a with $\mathbf{2 a}$ catalyzed by DBU give a Michael addition product $4 \mathbf{a}$ as an intermediate. Then retro-Claisen condensation is taken place through one carbonyl of $\mathbf{4 a}$ attacked by ethanol and subsequent carbon-carbon bond cleavage to give the final product $\mathbf{3 a}$.

\section{Conclusions}

In conclusion, a simple and effective protocol for the synthesis of 4-nitro-1,3-diarylbutan-1-ones through tandem reaction of 1,3-diarylpropan-1,3-diones and nitrostyrenes in the presence of DBU has developed. Although the loss of one acyl group makes the reactions poorly atom economical, mild reaction conditions, shorter reaction time, high yield, good functional group tolerance and simplified procedures are the salient features of this method. A gram-scale reaction has been attempted to illustrate the potency of reported procedure towards the bulk synthesis.

\section{Supporting Information (SI)}

The experimental details, analytical data, ${ }^{1} \mathrm{H}$ NMR and ${ }^{13} \mathrm{C}$ NMR spectra for the products are available at www.ias.ac.in/ chemsci.

\section{Acknowledgements}

The authors thank the National Natural Science Foundation of China (21462038) for the financial support of this work.

\section{References}

1. Heravi M M, Hajiabbasi P and Hamidi H 2014 Recent development in the asymmetric Michael addition for carbon-carbon bond formation Curr. Org. Chem. 18489

2. Jukic M, Sterk D and Casar Z 2012 Recent advances in the retro-Claisen reaction and its synthetic applications Curr. Org. Synth. 9488

3. Yu L, Cheng Y Y, Qi F, Li R and Li P F 2017 Organocatalytic regioselective, diastereoselective, and enantioselective annulation of cyclic 1-azadienes with $\gamma$-nitro ketones via 3,4-cyclization $\mathrm{Org}$. Chem. Front. 4 1336

4. Yu L, Cheng Y Y, Li R, Jiao Y H and Li P F 2016 Tandem cyclization reaction between optically active $\gamma$ nitro ketone and chalcone towards the synthesis of chiral cyclohexane skeletons bearing five stereocenters Chin. J. Org. Chem. 361572

5. Amireddy M and Chen K 2015 Organocatalytic synthesis of spirocyclohexane indane-1,3-diones via a chiral squaramide-catalyzed Michael/aldol cascade reaction of $\gamma$-nitro ketones and 2-arylideneindane-1,3-diones Tetrahedron 718003

6. Yu L, Yang Q J and Li P F 2014 Phase-transfer-catalystmediated domino reaction of $\gamma$-nitro ketones with chalcones: Approach to functionalized six-membered-ring carbocycles Eur. J. Org. Chem. 7499

7. Tishkov A A, Lyapkalo I M, Kozincev A V, Ioffe S L, Strelenko Y A and Tartakovsky V A 2000 Novel $\mathrm{Me}_{3} \mathrm{Si}$ mediated intramolecular cyclisation/[4+2] cyclofragmentation of $\beta$-substituted $\gamma$-nitro ketones Eur. J. Org. Chem. 3229

8. Zschiesche R and Reissig H U 1988 An efficient synthesis of 5-membered cyclic nitrones from $\gamma$-nitro ketones Tetrahedron Lett. 1685

9. Zhang G P, Zhu C, Liu D Y, Pan J K, Zhang J, Hu D Y and Song B A 2017 Solvent-free enantioselective conjugate addition and bioactivities of nitromethane to chalcone containing pyridine Tetrahedron $\mathbf{7 3} 129$

10. Ballini R, Barboni L, Castrica L, Fringuelli F, Lanari D, Pizzo F and Vaccaro L 2008 Polystyryl-BEMP as an efficient recyclable catalyst for the nucleophilic addition of nitroalkanes to $\alpha, \beta$-unsaturated carbonyl compounds under solvent-free conditions Adv. Synth. Catal. 350 1218

11. Li S S, Xie Z Y, Bian X Q and Wang C D 2007 New synthesis of 1,3-diaryl-4-nitro-1-butanones by microwavepromoted Michael addition of nitromethane to chalcones without solvent J. Chem. Res. 2007660

12. Oriyama T, Aoyagi M and Iwanami K 2007 Henry reaction and 1,4-addition of nitroalkanes to $\alpha, \beta$-unsaturated carbonyl compounds under the influence of MS 4A in DMSO Chem. Lett. 36612

13. Mancuso R, Palmieri A, Ballini R and Gabriele B 2012 Base-free conjugate addition of aliphatic nitro compounds to enones in $\mathrm{BmimNTf}_{2}$ : A recyclable synthesis of $\gamma$-nitro ketones Tetrahedron $\mathbf{6 8} 5852$

14. Barkov A Y, Korotaev V Y and Sosnovskikh V Y 2013 A novel synthesis of $\gamma$-nitro ketones via detrifluoroacetylative Michael addition of 1-trifluoromethyl-1,3-diketones to conjugated nitroalkenes Tetrahedron Lett. $\mathbf{5 4}$ 6819

15. Rasalkar M S, Potdar M K, Mohile S S and Salunkhe M M 2005 An ionic liquid influenced l-proline catalysed asymmetric Michael addition of ketones to nitrostyrene J. Mol. Catal. A Chem. 235267

16. Tsakos M, Kokotos C G and Kokotos G 2012 Primary amine-thioureas with improved catalytic properties for "difficult" Michael reactions: Efficient organocatalytic syntheses of (S)-baclofen, (R)-baclofen and (S)-phenibut Adv. Synth. Catal. 354740

17. Li B L, Wang Y F, Luo S P, Zhong A G, Li Z B, Du X $\mathrm{H}$ and Xu D Q 2010 Enantioselective Michael addition of aromatic ketones to nitroolefins catalyzed by bifunctional thioureas and mechanistic insight Eur. J. Org. Chem. 656

18. Wang L, Xu X, Huang J, Peng L, Huang Q and Wang L 2010 Asymmetric Michael addition of aromatic ketones 
to nitroolefins catalyzed by simple chiral bifunctional primary amine-thioureas Lett. Org. Chem. 7367

19. Jiang X, Zhang Y, Chan A S C and Wang R 2009 Highly enantioselective synthesis of $\gamma$-nitro heteroaromatic ketones in a doubly stereocontrolled manner catalyzed by bifunctional thiourea catalysts based on dehydroabietic amine: A doubly stereocontrolled approach to pyrrolidine carboxylic acids Org. Lett. 11 153

20. Flores-Ferrándiz J, Stiven A, Sotorríos L, GómezBengoa E and Chinchilla R 2015 Enantioselective addition of aryl ketones and acetone to nitroalkenes organocatalyzed by carbamate-monoprotected cyclohexa-1,2-diamines Tetrahedron Asymm. 26970

21. Chandrasekhar S, Kumar T P, Haribabu K, Reddy C R and Kumar C R 2011 A chiral pyrrolidinepyrazole catalyst for the enantioselective Michael addition of carbonyls to nitroolefins Tetrahedron Asymm. 22 697

22. Liu J, Yang Z, Liu X, Wang Z, Liu Y, Bai S, Lin L and Feng X 2009 Organocatalyzed highly stereoselective Michael addition of ketones to alkylidene malonates and nitroolefins using chiral primary-secondary diamine catalysts based on bispidine Org. Biomol. Chem. 7 4120

23. Huang H and Jacobsen E N 2006 Highly enantioselective direct conjugate addition of ketones to nitroalkenes promoted by a chiral primary amine-thiourea catalyst $J$. Am. Chem. Soc. 1287170

24. Sun Z, Peng F, Li Z, Zou L, Zhang S, Li X and Shao Z 2012 Enantioselective conjugate addition of both aromatic ketones and acetone to nitroolefins catalyzed by chiral primary amines bearing multiple hydrogenbonding donors J. Org. Chem. 774103

25. Liu K, Cui H, Nie J, Dong K, Li X and Ma J 2007 Highly enantioselective Michael addition of aromatic ketones to nitroolefins promoted by chiral bifunctional primary amine-thiourea catalysts based on saccharides Org. Lett. 9923

26. Evans D A, Mito S and Seidel D 2007 Scope and mechanism of enantioselective Michael additions of 1,3-dicarbonyl compounds to nitroalkenes catalyzed by nickel(II)-diamine complexes J. Am. Chem. Soc. 129 11583

27. Moon H W and Kim D Y 2012 Enantioselective decarboxylative Michael addition of $\beta$-ketoacids to nitroalkenes catalyzed by binaphthyl-derived organocatalysts Tetrahedron Lett. $\mathbf{5 3} 6569$

28. Li Z, Li T P, Li J S, He L L, Jia X G and Yang J Y 2015 2-Hydroxylation of 1,3-diketones with atmospheric oxygen Synlett 262863

29. Li Z, Song G Y, He J J, Du Y and Yang J Y 2017 Catalyst-free sulfa-Michael addition of pyrimidine-2thiol to nitroolefins J. Sulfur Chem. 38686 